\title{
Markers of mouse macrophage development detected by monoclonal antibodies
}

\author{
Pieter J.M. Leenen ${ }^{\text {a,* }}$, Marella F.T.R. de Bruijn ${ }^{\text {a }}$, Jane S.A. Voerman ${ }^{\text {a }}$, \\ Priscilla A. Campbell ${ }^{\text {, }}$, Willem van Ewijk ${ }^{\mathrm{a}}$ \\ a Department of Immunology, Erasmus University, P.O. Box 1738, 3000 DR Rotterdam, Netherlands \\ ${ }^{b}$ Division of Basic Immunology, National Jewish Center for Immunology and Respiratory Medicine, Denver, CO, USA
}

\begin{abstract}
In this review, we present and discuss a selected panel of antibody-defined markers expressed during different stages of mouse macrophage development. We distinguish four categories of markers, which are characteristic of: (1) macrophage precursors and immature macrophages (ER-MP12, ER-MP20, ER-MP54, ER-MP58); (2) mature macrophages in general (F4/80, BM8, Mac-1, Mac-2, ER-BMDM1); (3) macrophage subsets (ER-HR3, ER-MP23, ER-TR9, Forssman antigen, MOMA-1, MOMA-2, Monts-4, SER-4), and (4) IFN- $\gamma$-stimulated macrophages (H-2Ia, LFA-1, ICAM-1, 158.2, MBR-2, TM-2, TM-4, and TM-5). It should be noted that many of the markers in this last category are inducible by other stimuli as well. The rigid classification of markers into four separate groups should be regarded as a digitalization of a continuum, thus inevitably implicating a simplification of the complex phenotypic changes that occur during mononuclear phagocyte development. Nevertheless, the current selection of antibodies against markers for different developmental stages of macrophages constitutes an important tool for characterization of mouse macrophages which participate in various biological processes.
\end{abstract}

Keywords: Mononuclear phagocyte; Monoclonal antibody; Phenotypic analysis

\section{Introduction}

The cell surface of the mouse macrophage has been mapped extensively since the introduction of hybridoma technology in the late seventies. An array of monoclonal antibodies elicited against different macrophage populations has been pro-

\footnotetext{
* Corresponding author. Tel.: +31-10-408 7181; Fax: +3110-436 7601 .
}

duced and characterized (see Leenen and Campbell, 1993 for an overview). Yet, defining discrete, functional stages in mouse macrophage development using antibodies against discriminating determinants appeared to be much more complicated than describing functionally distinct lymphocyte subtypes.

The limited insight into the link between phenotype and function of different macrophage populations may be ascribed primarily to the complexity of the mononuclear phagocyte system (see elsewhere in this volume and recent reviews 
by us and others (Leenen and Campbell, 1993; Rutherford et al., 1993). Different macrophages are involved in a wide variety of processes, such as (1) clearance of potentially harmful substances, (2) killing of microorganisms and tumor cells, (3) regulation of and participation in inflammatory and immune responses, and (4) regulation of hemo-and lymphopoiesis. This functional diversity is clearly reflected in the phenotypic diversity of the various mononuclear phagocyte populations, although it is often difficult to interpret observed phenotypic differences.

In this review, we will discuss a selected panel of markers, detected by monoclonal antibodies, useful for the phenotypic characterization of mouse macrophages. Emphasis will be on the interpretation of phenotypic characteristics - and on the limitations thereof - in terms of macrophage developmental stages and functional capabilities. To that end, we will first attempt to define the different processes in macrophage development, since many slightly different definitions are being used in the field.

We regard the phenotypic and functional changes that macrophages undergo during development as being caused by either maturation, differentiation, or activation of the cells (schematically depicted in Fig. 1). Maturation is the process by which cells acquire features typical of cells in later stages of development, and lose aspects of earlier stages. Differentiation, in our view, is a specific type of maturational process by which diversity is generated. Both maturation and differentiation are, in principle, irreversible. In contrast, activation of macrophages is a reversible process by which cells are stimulated to express particular functions or by which the accomplishment of certain existing functions is enhanced. These processes may occur concurrently, that is, a cell might both mature and become activated as a response to a specific stimulus.

In accordance with the different developmental processes, macrophage markers may be classified as (1) maturation markers, which are either positively or negatively correlated with the cell's maturation stage, (2) differentiation or subset markers, which are expressed differentially by cells of similar maturation stages, and (3) activa-

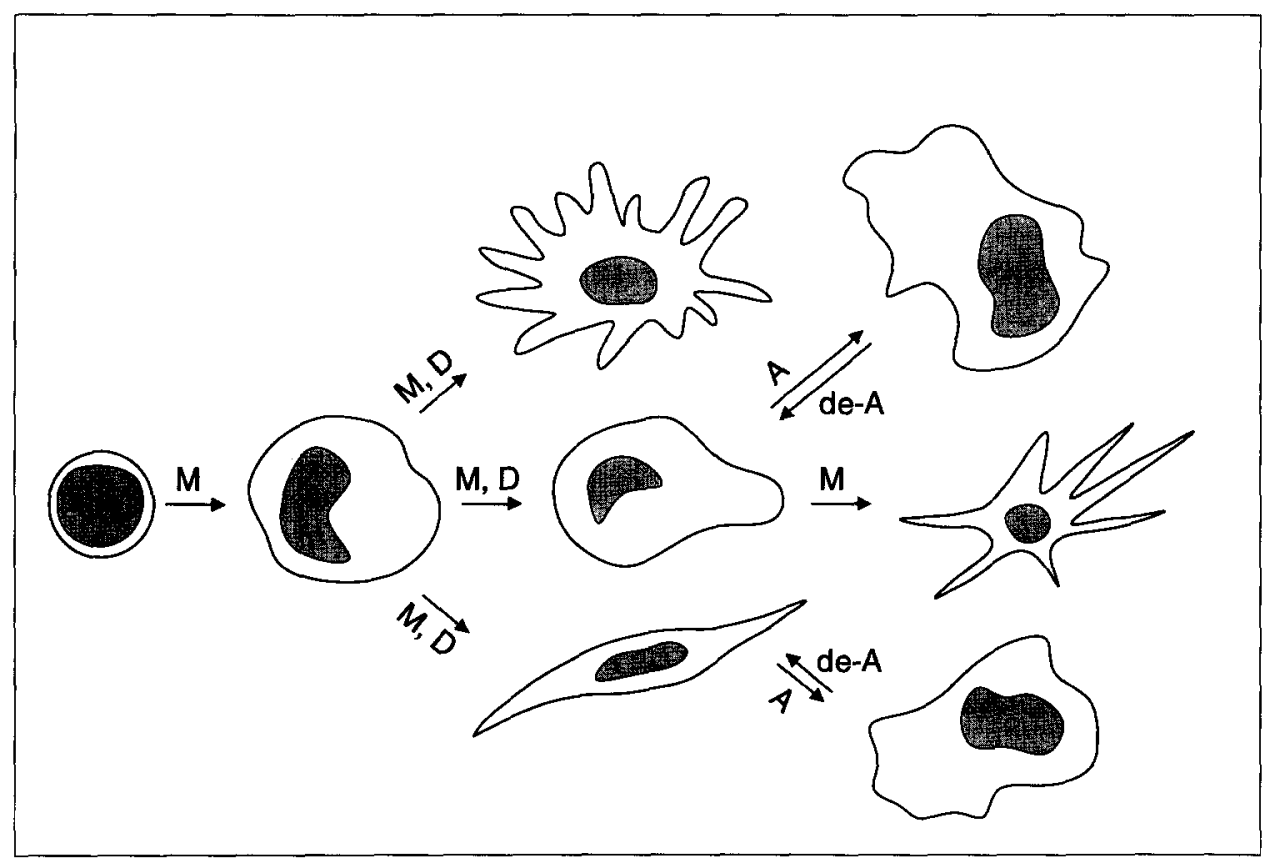

Fig. 1. Schematic representation of different facets of macrophage development. $M=$ maturation; $D=$ differentiation; $A=$ activation; de- $\mathbf{A}=$ de-activation. 
tion markers, whose expression can be induced or enhanced by particular external stimuli and is indicative of certain functional capabilities. Inevitably, the assignment of a particular marker to one of these categories depends significantly on the experimental models used to study maturation, differentiation and activation.

In our previous work, we have adopted and developed three different models for the identification of macrophage maturation markers, recognized by newly prepared and existing monoclonal antibodies. The first model consists of a panel of macrophage cell lines, which can be aligned in order of increasing maturity and represent stages ranging from CFU-GM to relatively mature exudate macrophages (Leenen et al., 1986). M-CSFstimulated bone marrow (BM) cell cultures abrogated at different time points provides a second maturation model (cf. Van der Meer et al., 1983, Walker et al., 1985). Thirdly, multiple macrophage precursor cell lines can be stimulated to develop into more mature stages by external stimuli, such as mouse post-endotoxin serum (Leenen et al., 1990a).

Models for the identification of macrophage differentiation or subset markers are not as clearly defined as the maturation models mentioned above. In the latter, homogeneous populations of mature cells are generated from precursors, and diversification, which is by definition the hallmark of differentiation, is rarely observed. Yet, different macrophage subsets can be easily discerned in situ by immunohistochemical analysis of complex organs such as the spleen (Van Rooijen et al., 1989). Here, phenotypically distinct macrophage subsets are found in different microanatomical locations. The developmental relationship between these subsets is unclear, but the cells do not show conclusive maturational differences that might explain their phenotypic heterogeneity. However, at some point in their development the distinct macrophage subsets share a common progenitor and thus represent the endstages of a differentiation process. Therefore, to identify different subset markers we use immunohistochemistry of macrophages in lymphoid and non-lymphoid organs as the main technique.

Macrophage activation markers are, by defini- tion, induced by specific external stimuli and the expression of these markers decreases again when the stimulus is removed. As a screening model, macrophage cell lines or primary BM cultures are stimulated with IFN- $\gamma$, which is known to mediate several functional changes in a broad spectrum of macrophages. For instance, IFN- $\gamma$ stimulated macrophages show increased ability to present antigen to $\mathrm{CD}^{+} \mathrm{T}$ cells, as a consequence of increased MHC class II expression, and are primed for further stimulation to become tumoricidal (Adams and Hamilton, 1984). However, stimulating macrophages with IFN- $\gamma$ precludes the development of other functional stages. Thus, in general, activation markers are linked directly to the type of stimulus given, as well as to the type of responding macrophage.

In the following sections we will discuss a panel of macrophage markers, classified as either immature or mature markers, subset markers or activation markers according to the criteria mentioned above. Unfortunately, the discussion will show that very few of these markers, if any, are fully specific for a single category. Our experience is that the same holds true for other macrophage markers not included in the present selection. Yet, using combinations of multiple markers from the different categories for the phenotyping of mouse macrophages permits a plausible description of their developmental stage in terms of relative (im)maturity, belonging to a particular subset or being (un)stimulated.

\section{Materials and methods}

\subsection{Bone marrow cultures}

Macrophage development was followed in liquid bone marrow cultures stimulated with M-CSF, as described before (Leenen et al., 1990a). Briefly, bone marrow was harvested from BALB/c mice (10-20 weeks of age), which had been kept under clean, routine conditions in accordance with institutional guidelines for animal welfare. The cells obtained were cultured for various periods of time in DMEM, supplemented with $10 \%$ fetal 
calf serum, $13 \%$ L-cell conditioned medium and antibiotics, and then phenotypically analyzed.

\subsection{Monoclonal antibodies}

The characteristics of and references for monoclonal antibodies (mAbs) described in this paper are summarized in Table 1 . Hybridomas marked with "ER-" were established in our own department; M1/70, M3/38, M1/22.25, M5/114, YN1/1.7 and MA158.2 producing hybridomas were obtained from the American Type Culture Collection (Rockville, MD); mAbs and/or hybridomas designated BM8, F4/80, H35.89, MOMA-1, MOMA-2, Monts-4, MIV 38, SER-4, TM-2, TM-4, and TM-5 were kindly provided by the respective producers and/or BMA Biomedicals AG (Augst, Switzerland). For cellular staining, either undiluted hybridoma supernatants or optimally diluted purified antibody preparations were used.

\subsection{Immunofluorescence staining and flowcytomet- ric analysis}

Staining of cells was performed using routine procedures, essentially as described before (Leenen et al., 1990b). Cellular fluorescence as a measure of antibody binding was determined using a FACScan (Becton Dickinson, Sunnyvale, CA) with logarithmic amplification of FITC fluorescence signals. Results are expressed either as percent positive cells compared to cells stained with a control $\mathrm{mAb}$, or as molecules equivalent to soluble FITC (MESF). The latter values were obtained by interpolation of cellular fluorescence values compared to a standard curve prepared using microspheres of known fluorescence intensity (Flow Cytometry Standards, Research Triangle Park, NC).

\section{Results and discussion}

Table 1 shows a selection of monoclonal antibodies directed against markers of different mouse macrophage developmental stages, i.e., universal immature and mature macrophage markers, subset markers, and macrophage activation markers. As outlined above, the distinction between the different marker categories is not always absolute. In particular, the discrimination between universal mature macrophage markers and subset markers is more or less arbitrary, since no markers exist, to our knowledge, that are expressed by all macrophages, and are relatively specific for these cells. In other words, all mature macrophage markers are in fact subset markers. Yet, a distinction between the two categories is made on the basis of the widespread expression of universal mature markers by macrophages in vitro as well as in vivo, and the more restricted occurrence of subset markers.

\subsection{Immature macrophage markers}

The panel of immature macrophage markers, ER-MP12, -20, -54, and -58, has been generated against macrophage precursor hybrid cell lines and selected for the recognition of markers expressed preferentially by immature stages of maturation using in vitro models (Leenen et al., 1990b). The decreasing expression of these markers upon maturation of macrophages is clearly illustrated by the decreasing percent of cells positive for these markers during M-CSF-stimulated BM culture (Fig. 2). Additional studies by ourselves and others have confirmed and extended the initial characterization of these markers (Wijffels et al., 1993; McCormack et al., 1993; De Bruijn et al., manuscript submitted).

Using these markers for identification of macrophage precursor cells, it should be realized that, in the macrophage lineage, ER-MP12, -20, -54 and -58 antigens are restricted to precursor stages, but these markers are also expressed by other cell types. In recent experiments, about $40 \%$ of freshly isolated BM cells were repeatedly found positive for ER-MP12, in contrast with 6-9\% assessed earlier using less advanced technology (cf. Leenen et al., 1990b; Slieker et al., 1993a). This significant percent of BM cells found positive for ER-MP12 already indicates that other hemopoietic cells are recognized as well. ERMP12 also detects pluri- and multipotent stem cells and prothymocytes in BM as well as particu- 
lar lymphoid cells in BM and peripheral lymphoid organs (Slieker et al., 1993a,b; De Bruijn et al., manuscript submitted; Van der Loo et al., manuscript in preparation). Although the identity of the ER-MP12 antigen has not yet been established, it bears similarity to CD34 with regard to high level expression by early hemopoietic cells.

The antigen recognized by ER-MP20 has been

Table 1

Monoclonal antibodies against markers of mouse macrophage development

\begin{tabular}{|c|c|c|c|c|}
\hline $\mathrm{mAb}$ & Antigen & $\begin{array}{l}\text { Mol. mass } \\
(\mathrm{kDa})\end{array}$ & Ag description & Reference(s) \\
\hline \multicolumn{5}{|c|}{ Immature macrophage markers } \\
\hline ER-MP12 & & 140 & Single chain (glyco)protein & Leenen et al., $1990 \mathrm{~b}$ \\
\hline ER-MP58 & & & & Leenen et al., 1990b \\
\hline ER-MP54 & & $\begin{array}{l}90,80-85 \\
70-75\end{array}$ & & Leenen et al., $1990 \mathrm{~b}$ \\
\hline ER-MP20 ${ }^{a}$ & Ly-6C & 14 & Glycoprotein, usually PI-linked & Leenen et al., $1990 \mathrm{~b}$ \\
\hline \multicolumn{5}{|c|}{ Mature macrophage markers } \\
\hline $\mathrm{F} 4 / 80^{\mathrm{a}}$ & & 160 & Single-chain glycoprotein & Austyn and Gordon, 1981 \\
\hline BM8 & & 125 & & Malorny et al., 1986 \\
\hline $\mathrm{M} 1 / 70^{\mathrm{a}}$ & $\begin{array}{l}\text { Mac- } 1 \alpha \\
\text { CD } 11 b \\
\text { Ly-40 }\end{array}$ & 170 & $\begin{array}{l}\text { CR } 3 \alpha \text {, fibrinogen } \mathbf{R}^{\mathrm{b}} \text {, clot- } \\
\text { ting factor } \mathrm{X} \mathrm{R} \text {, adhesion } \\
\text { molecule }\end{array}$ & $\begin{array}{l}\text { Springer et al., } \\
1979\end{array}$ \\
\hline $\mathrm{M} 3 / 38^{\mathrm{a}}$ & $\begin{array}{l}\text { Mac-2, } \\
\text { CBP35 }\end{array}$ & $32-35$ & $\begin{array}{l}\text { Galactose-specific lectin; IgE- } \\
\text { and laminin-binding protein }\end{array}$ & $\begin{array}{l}\text { Ho and Springer, } \\
1982\end{array}$ \\
\hline ER-BMDM1 ${ }^{a}$ & CD13? & 160 & Aminopeptidase $\mathrm{N}$ & Leenen et al., 1992 \\
\hline \multicolumn{5}{|c|}{ Macrophage subset markers } \\
\hline ER-HR3 & & $\begin{array}{l}76,67 \text { (non- } \\
\text { red.) } \\
69,55 \text { (red.) }\end{array}$ & $\begin{array}{l}\text { Two distinct single chain } \\
\text { (glyco-)proteins; high } M_{\mathrm{r}} \\
\text { form secreted }\end{array}$ & $\begin{array}{l}\text { De Jong et al., } \\
\text { 1994a,b }\end{array}$ \\
\hline ER-MP23 & & 38 & Single chain (glyco-)protein & Leenen et al., 1991 \\
\hline ER-TR9 & & & $\begin{array}{l}\text { Involved in } \mathrm{M} \phi \text { neutral } \\
\text { polysaccharide uptake }\end{array}$ & $\begin{array}{l}\text { Van Vliet et al., } \\
1985\end{array}$ \\
\hline $\mathrm{M} 1 / 22.25^{\mathrm{a}}$ & $\begin{array}{l}\text { Forssman } \\
\mathrm{Ag}\end{array}$ & & Glycosphingolipid hapten & $\begin{array}{l}\text { Springer et al., } \\
1978\end{array}$ \\
\hline MOMA-1 & & & & Kraal and Janse, 1986 \\
\hline MOMA-2 & & & & Kraal et al., 1987 \\
\hline Monts-4 & & $80-100$ & (Glyco-)protein & Jutila et al., 1993 \\
\hline SER-4 & $\begin{array}{l}\text { SER; sialo- } \\
\text { adhesin }\end{array}$ & $170-185$ & Sialylated glycoconjugate $\mathbf{R}$ & $\begin{array}{l}\text { Crocker and } \\
\text { Gordon, } 1989\end{array}$ \\
\hline \multicolumn{5}{|c|}{ Macrophage activation markers } \\
\hline $\mathrm{M} 5 / 114^{\mathrm{a}}$ & H-2Ia & $25-34$ & $\begin{array}{l}\text { Heterodimer; Ag-peptide } \\
\text { binding for presentation }\end{array}$ & $\begin{array}{l}\text { Bhattacharya et } \\
\text { al., } 1981\end{array}$ \\
\hline $\mathrm{H} 35.89^{\mathrm{a}}$ & $\begin{array}{l}\text { LFA- } 1 \alpha \\
\text { CD11a }\end{array}$ & 180 & CD54 and ICAM-2 ligand & $\begin{array}{l}\text { Pierres et al., } \\
1982\end{array}$ \\
\hline $\mathrm{YN} 1 / 1.7^{\mathrm{a}}$ & $\begin{array}{l}\text { ICAM-1, } \\
\text { MALA-2, } \\
\text { CD54 }\end{array}$ & 95 & CD11/CD18 ligand & Takei, 1985 \\
\hline MA158.2 & 158.2 & & & Koestler et al., 1988 \\
\hline MIV $38^{a}$ & MBR-2 & & & Martin et al., 1988 \\
\hline TM-2 & & 45 & & Paulnock and Lambert, 1990 \\
\hline TM-4 & & & & D.M. Paulnock, personal comm. \\
\hline TM-5 & & & & D.M. Paulnock, personal comm. \\
\hline
\end{tabular}

Also other mAbs with the same or similar reactivities have been reported.

${ }^{b} \mathbf{R}=$ receptor. 
identified definitively as Ly-6C (McCormack et al., 1993) and is expressed by monocytes and granulocytes, as well as by a subpopulation of $\mathrm{CD}^{+} \mathrm{T}$ cells. Quantitative analysis of ER-MP20 antigen expression permits the identification of monocytes in BM as these cells show the highest antigen levels (De Bruijn et al., manuscript submitted). BM macrophage colony-forming cells (M-CFC) are either ER-MP20 negative or show an intermediate level. The former are the most immature: they produce the largest colonies and pass through an ER-MP20 positive stage upon maturation in vitro (De Bruijn et al., manuscript submitted). Mature macrophages, however, are ER-MP20 negative. Therefore, ER-MP20 is a typical marker of intermediate stages of BM-derived macrophage maturation. Surprisingly, in spleen all M-CFC are found in the ER-MP20 ${ }^{\text {hi }}$ fraction, whereas no M-CFC are present in the corresponding fraction in BM (McCormack et al., 1993). Although the origin of this distinction is not known, it is possible that environmental differences determine expression of the ER-MP20 antigen by macrophage progenitors: the antigen is significantly induced or up-regulated after interferon- $\gamma$ or interferon- $\alpha / \beta$ stimulation (unpublished and Jutila et al., 1988). The inducibility of
ER-MP20 antigen expression is strikingly maturation-stage-dependent, as it can be induced in immature cells, but not in mature macrophages.

The ER-MP54 antigen was selected as a surface marker of macrophage precursor cell lines, but appeared to be absent from the cell surface of normal BM cells (Leenen et al., 1990b). Instead, BM cells express this marker only cytoplasmically. Specific experimental conditions, such as corticosteroid treatment in vitro, may induce ERMP54 surface expression on some non-transformed cells (unpublished). Immunohistological examination shows an ER-MP54 antigen distribution that is restricted to presumed myeloid cells: the majority of BM cells and some clusters in the splenic red pulp (unpublished).

ER-MP58 demonstrates a similar, relatively specific, staining of myeloid cells in sections of BM and spleen (unpublished). Yet, this marker is present on the cell surface of the majority of normal BM cells, including virtually all M-CSFresponsive macrophage precursors (Leenen et al., 1990b). Expression of ER-MP58 decreases significantly upon maturation of macrophages. However, reduced levels can still be demonstrated on BM-derived macrophages in vitro (Fig. 2) as well as on some macrophage cell lines with mature

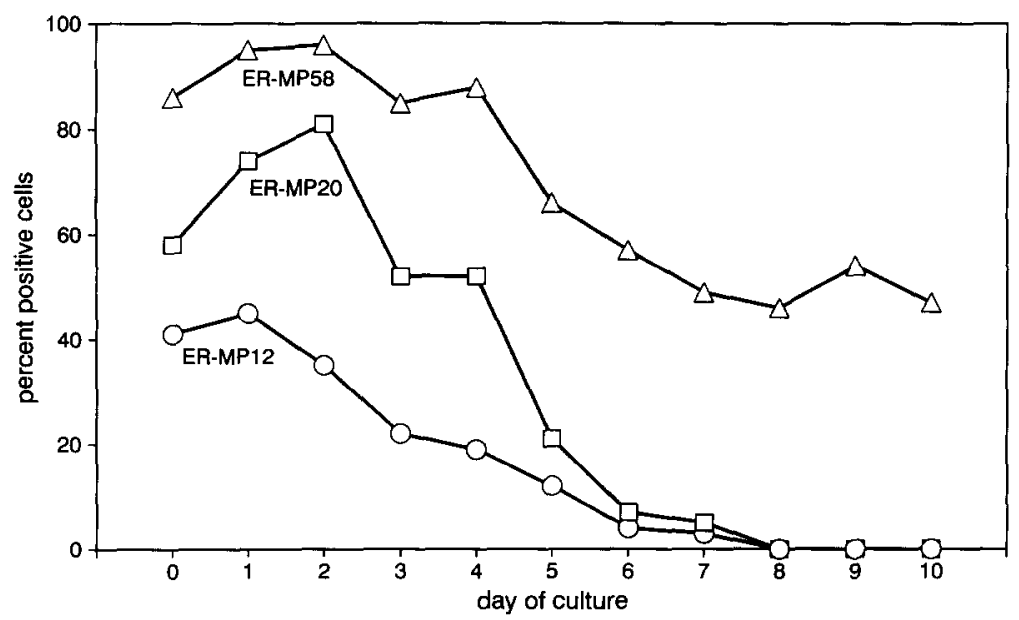

Fig. 2. Expression of immature macrophage markers in M-CSF-stimulated BM culture. Cells were harvested at different time points from liquid BM cultures and analyzed phenotypically using flow cytometry. The number of morphologically identifiable mononuclear phagocytes (i.e., monoblasts, (pro)monocytes and macrophages) in these cultures increases from less than $10 \%$ at day 0 to $60-70 \%$ at day 4 and $>98 \%$ at day 7 . Data represent the mean net percent of marker-positive cells, compared to negative control values, as determined in at least two experiments; the standard deviations were less than $10 \%$. 
features. Thus, high level ER-MP58 expression is characteristic of precursor cells, although the marker may be retained by some macrophages in more mature stages.

Taken together, the markers detected by ERMP12, $-20,-54$, and -58 are expressed selectively by immature cells of the macrophage lineage. However, other cell types may be positive for these markers as well, suggesting that expression of one or more of these antigens does not necessarily identify the cells under study as macrophage precursors. If, on the other hand, the macrophage identity of such cells has been established, then expression of ER-MP12, -20, -54 and/or -58 anti- gens is highly suggestive of their immature nature.

\subsection{Mature macrophage markers}

The panel of universal mature macrophage markers that we regularly use to demonstrate macrophage maturity includes F4/80, BM8, Mac1, Mac-2 and ER-BMDM1. Fig. 3 shows the expression of these markers during M-CSFstimulated BM culture. Despite the differences found in the percent of positive cells in freshly isolated $\mathrm{BM}$, all of these markers are expressed uniformly by the mature macrophages obtained
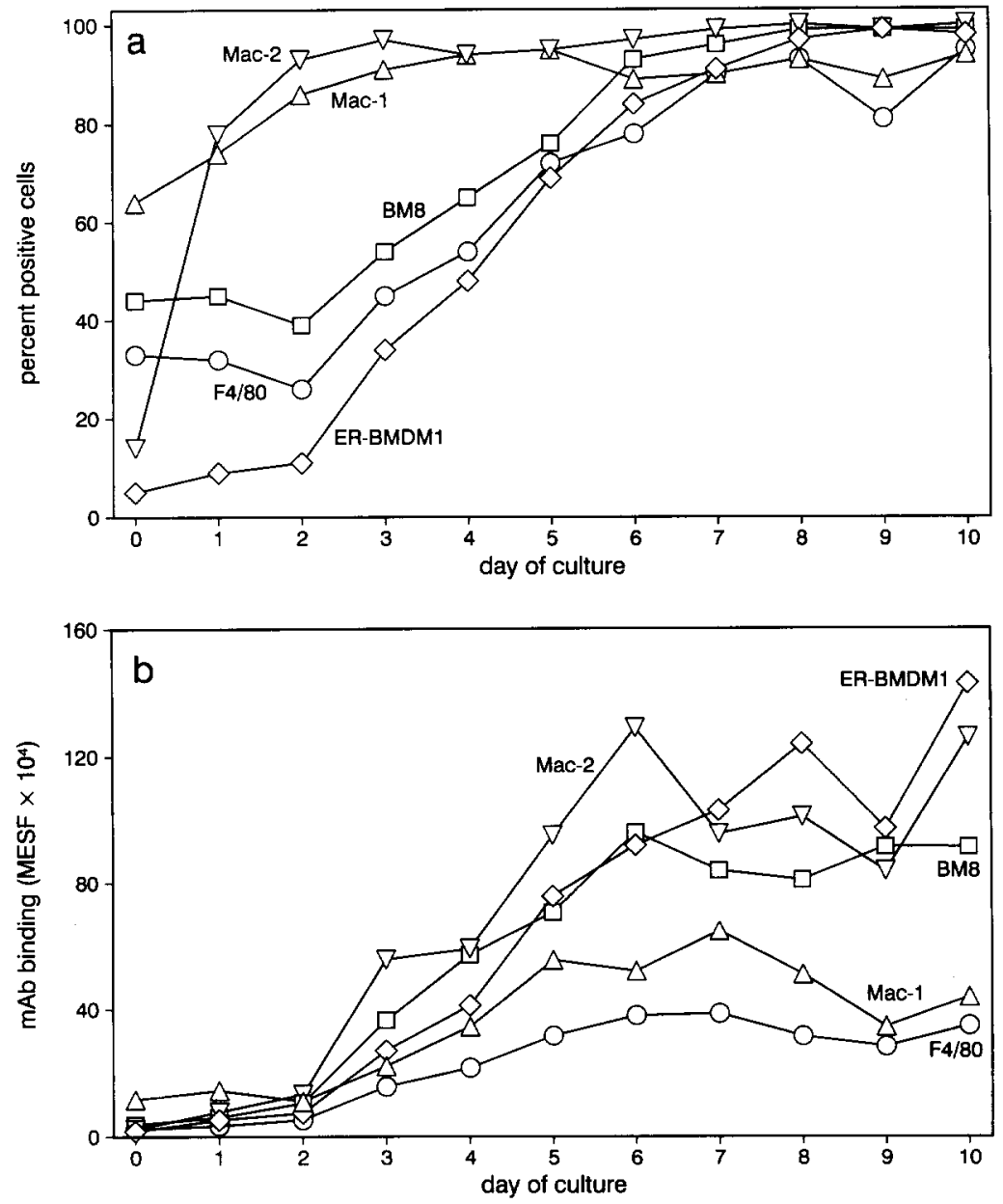

Fig. 3. Expression of universal mature macrophage markers in M-CSF-stimulated BM culture. $a$ : mean net percent of marker-positive cells at different time points during in vitro macrophage development (cf. legend Fig. 2); $b$ : quantitative analysis of mAb binding to developing macrophages. Data represent the mean net antibody binding to the marker-positive cells depicted in $a$. 
from day 7 and beyond (Fig. 3a). Not only does the percentage of positive cells increase in these cultures as macrophages mature, the level of antibody binding per cell increases even more dramatically, indicating enhanced antigen expression by more mature cells (Fig. $3 b$ ). The differential staining of fresh BM for the different markers clearly reflects the presence (e.g., Mac-1) or absence (e.g., ER-BMDM1) of these markers on other hemopoietic cell types, especially myeloid cells.

The F4/80 antigen is perhaps the most universal and widely used macrophage marker with relative specificity for this cell type. Expression of this marker commences early during macrophage development, but after the M-CFC stage (Hirsch et al., 1981). In vitro, most if not all mature macrophages express the $\mathrm{F} 4 / 80$ antigen, but in vivo some macrophage populations do not show detectable F4/80 antigen levels, especially those in lymphoid microenvironments (Witmer and Steinman, 1984). This lack of significant antigen expression may be due to high local concentrations of lymphocyte-derived cytokines, some of which have been shown to down-regulate F4/80 antigen expression (Ezekowitz and Gordon, 1982). F4/80 is a selective, but not an exclusive marker for macrophages, since freshly isolated eosinophils as well as endothelial-like cells in BM stromal cultures bind the F4/80 antibody (McGarry and Stewart, 1991; Penn et al., 1993).

BM8 is a macrophage marker that bears significant similarity to F4/80 (Malorny et al., 1986). Although the apparent molecular masses of these antigens are different, $125 \mathrm{kDa}$ for BM8 vs. 160 $\mathrm{kDa}$ for $\mathrm{F} 4 / 80$, the staining patterns obtained show a high degree of overlap. The original description of BM8 showed expression of the antigen only by cells beyond the monocytic stage. In our hands, however, monocytes and myeloid precursors also specifically bind small, but detectable amounts of the BM8 antibody as demonstrated by sensitive flow cytometry.

The Mac-1 (CD11b/CD18) antigen was one of the first macrophage markers defined by monoclonal antibody (Springer et al., 1979). Expression of Mac-1 is detected on cells beyond the M-CFC stage in bone marrow and spleen (Miller et al.,
1985; McCormack et al., 1993) and increases significantly with maturation of macrophages in vitro (Walker et al., 1985). Yet, Mac-1 is undetectable on many "tissue-fixed" macrophages, but is expressed at different levels by virtually all "free" macrophage populations (Flotte et al., 1983; Nibbering et al., 1987). In addition, granulocytes and NK cells express Mac-1 as well as activated and memory $\mathrm{CD}^{+}$cytotoxic $\mathrm{T}$ cells and some unusual B-1 lymphocytes (Springer et al., 1979, Holmberg et al. 1981, Miyama-Inaba et al., 1988, McFarland et al., 1992). Using blocking studies, it was found that anti-Mac-1 mAb recognized the $\alpha$-chain of type 3 complement receptor, a member of the integrin family (Beller et al., 1982). This receptor is involved in adhesive processes with different ligands. First of all, CR3 mediates uptake of opsonized microorganisms and particles by binding of iC3b and C3d (reviewed by Brown, 1991). In addition, it was shown for macrophage - Listeria interactions, that CR3 not only functions as a receptor for internalization but also seems to trigger processes essential for killing of the bacterium (Drevets et al., 1993). Second, CR3 binds other molecules, such as fibrinogen and clotting factor $\mathrm{X}$, mostly through an Arg-Gly-Asp containing sequence in the ligand (Brown, 1991). Third, CR3 is critically involved in the recruitment of myelomonocytic cells in response to various inflammatory stimuli, probably by binding to ICAM-1 (CD54) molecules on the inflamed endothelium (reviewed by Rosen, 1990).

Mac-2 was originally presented as a macrophage subpopulation-specific marker ( $\mathrm{Ho}$ and Springer, 1982). However, expression of this antigen closely correlates with macrophage maturation in all in vitro models (Fig. 3; Leenen et al., 1986, 1990a; Walker et al., 1985). It is induced in precursor cells at a relatively late stage, just preceding the ability of cells to become adherent. Cloning and sequencing of the Mac- 2 gene showed that it does not contain a classic signal peptide or transmembrane domain, indicating that it is mainly an intracellular protein (Cherayil et al., 1989). This is confirmed by the finding that the percentage of Mac- 2 positive spleen cells increases from about $20 \%$ to more than $70 \%$ upon permeabilization of the cell membrane 
(Leenen et al., 1987). The latter finding also implies that many cell types other than macrophages also express the Mac-2 antigen. Mac-2 has been identified as a galactose-specific lectin. Cell surface expression may thus be explained by binding of secreted molecules to surface-bound glycan moieties, since binding is abolished by incubation of cells in the presence of competing sugar (Frigeri and Liu, 1992).

The ER-BMDM1 Ag is, of the universal mature markers described here, induced last on developing macrophages (Fig. 3). BM cells as well as blood monocytes are essentially ER-BMDM1 negative, and expression is observed uniformly on all mature cells in the various models (Leenen et al., 1992). In vivo, however, only specific macrophage subpopulations are detected by this antibody, including about one third of the resident peritoneal and alveolar macrophages. Certain inflammatory macrophages, such as thioglycollate-elicited cells, express high levels of this marker. Furthermore, populations belonging to the dendritic leukocyte lineage are mostly ERBMDM1 positive. The biochemical characteristics of the antigen - a molecular mass of $160 \mathrm{kDa}$ and demonstrated aminopeptidase $\mathrm{N}$ activity suggest that this marker is the mouse homologue of human CD13 (Leenen et al., 1992).

\subsection{Macrophage subset markers}

As outlined before, the distinction between universal mature macrophage markers and subset markers is more or less arbitrary. Our criterion for classification is that subset markers are not universally expressed by all mature macrophages in the in vitro maturation models, in contrast to the universal mature markers. Also, subset markers show a restricted distribution in vivo (see below). The subset markers that we use (ER-HR3, ER-MP23, ER-TR9, Forssman Ag, MOMA-1, MOMA-2, Monts-4, and SER-4) are typical of different macrophage subsets in tissue sections of various organs, and all, except Forssman antigen, show a high degree of specificity for mononuclear phagocytes.

The macrophage subset marker ER-HR3 is expressed by a specific subpopulation of mouse macrophages, located especially in hemopoietic organs: bone marrow and splenic red pulp (De Jong et al., 1994a,b). The number of ER-HR3 positive macrophages in the red pulp constitutes only a subset of all (F4/80 positive) red pulp macrophages, yet includes the so-called central macrophages of the erythropoietic islands. Induction of extramedullary hemopoiesis in the liver by phenylhydrazine treatment of mice is accompanied by the appearance of ER-HR3 positive central macrophages. This observation supports the notion that the ER-HR3 positive macrophage subset is functionally involved with erythropoietic activity (De Jong et al., 1994b). Yet, other subsets which are not apparently involved with hemopoietic activity, such as those located in the lymph node paracortex and the ileal lamina propria, also express the ER-HR3 antigen (De Jong et al., 1987).

ER-MP23 is a marker particularly expressed by connective tissue macrophages, or histiocytes (Leenen et al., 1991). Interestingly, macrophages in many, but not all, connective tissues located near epithelia express high levels of this antigen: e.g. dermal macrophages and macrophages in the reticular connective tissue of the submandibular gland are strongly ER-MP23 positive, but those in the intestinal lamina propria are generally ERMP23 negative. In addition to a location in connective tissue, ER-MP23 positive cells may also occur sparsely in lymphoid tissues. Furthermore, ER-MP23 positive non-lymphoid cells, being either macrophages or dendritic leukocytes, are among the first cells to infiltrate the pancreatic islets of the pre-diabetic NOD mouse (Jansen et al., 1994). In vitro studies of ER-MP23 expression among different macrophage populations and derived cell lines have indicated that macrophages are either strongly positive for this marker, or negative/dull. This ER-MP23 phenotype of in vitro maintained cells is surprisingly stable; in our hands, an ER-MP23-/dull cell line could not be converted by a variety of stimulants into an ERMP23 $3^{\text {hi }}$ cell line and vice versa (Leenen et al., 1991). This led us to conclude that ER-MP23 might be a subset marker characteristic of a distinct lineage of macrophage development.

ER-TR9 antigen expression is characteristic of 
splenic marginal zone macrophages and macrophages located in the medullary and trabecular sinuses of lymph nodes (Van Vliet et al., 1985; Dijkstra et al., 1985). These highly phagocytic populations are unique in their ability to retain and ingest neutral polysaccharides, such as Ficoll and dextran. Interestingly, in vivo administration of the ER-TR9 antibody abolished endocytosis of these polysaccharides, but did not influence the ability to ingest latex or carbon particles (Kraal et al., 1989). The ER-TR9 mAb probably does not recognize the binding site of the neutral polysaccharide receptor, since injection of polysaccharides prior to administration of the antibody did not diminish binding of the latter.

The Forssman glycolipid antigen ( $\mathrm{Fo}$ ) is expressed by a subset of stromal macrophages mainly associated with early hemo-lymphopoietic development: macrophages in bone marrow stroma, splenic red pulp, and thymic cortex (Sadahira et al., 1988, Mühlradt et al., 1989). Furthermore, medullary macrophages in inguinal and axial lymph nodes, but not in mesenteric lymph nodes, express Fo. This marker is less specific for mononuclear phagocytes than the other subset markers from the present selection; in adult tissues also reticular cells in various organs and thymic epithelial cells are $\mathrm{Fo}^{+}$, whereas developing mesenchymal cells express Fo transiently. Fo expression is inducible by IL-4 or IL-6 in a small percent of macrophages in a specific stage of development (Kleist et al., 1990).

The antigen recognized by MOMA-1 is expressed by a macrophage subset typified by the metallophilic macrophages at the white pulp side of the marginal sinus in the spleen, and capsular and medullary sinus macrophages in peripheral lymph nodes (Kraal and Janse, 1986). These populations are characterized by a high level of nonspecific esterase activity, which, linked to their strategic location, is suggestive of a degrading and detoxifying function (Kraal, 1992). Injection of the MOMA-1 mAb into neonatal mice led to a significant reduction of the presence of MOMA-1 positive cells, and concomitantly, to impaired humoral immune responses against thymus-dependent (TD) and thymus-independent type 2 (TI-2) antigens (Kraal et al., 1988). This suggests a role for the marginal metallophilic macrophages in the presentation of these antigens, although in the neonate a subpopulation of cells located in the red pulp also shows MOMA-1 expression and may thus be involved in the immune response against TD and TI-2 antigens.

The MOMA-2 mAb is especially useful for the identification of macrophages in lymphoid tissues (Kraal et al., 1987). Most, if not all, macrophages in lymphoid microenvironments show high level expression of this marker. The antigen is located primarily in the cytoplasm, but it can also be demonstrated on the cell surface. The expression of the MOMA-2 antigen shows a high degree of similarity with the expression of acid phosphatase, including the localization of both markers to a cytoplasmic region of dendritic leukocytes. MOMA-2 is expressed early during the development of mononuclear phagocytes, since a significant fraction of $\mathrm{BM}$ cells as well as all blood monocytes are positive.

Immunohistological examination of the expression of the Monts-4 antigen suggests that this marker is expressed by both MOMA-1 and MOMA-2 positive subsets (Jutila et al., 1993). Yet, many macrophage populations do not express Monts-4, including most splenic red pulp macrophages. Expression of the antigen decreases quickly upon culture of isolated Monts- $4^{+}$ macrophages, suggesting the necessity of continuous stimulation for Monts-4 expression. In agreement with this, we have never observed significant Monts- 4 antigen expression by in vitro maintained macrophages, including transformed as well as growth factor-dependent cell lines and BM-derived macrophages.

The macrophage subset marker SER, identified by mAb SER-4, has been characterized most extensively in relation to the function of the antigen and the antigen-expressing macrophages in hemopoiesis (Crocker and Gordon, 1989). Initially identified as a receptor for sheep erythrocytes, SER is now also known as sialoadhesin, a receptor for sialylated glycoconjugates occurring on developing hemopoietic cells. Antibodies against SER are able to block interactions between sialylated compounds and SER. Interestingly, ligand binding to SER does not induce 
phagocytosis, suggesting that SER's primary function is to maintain physical contact between cells and/or mediate signal transduction. The receptor is expressed by stromal macrophages at hemopoietic sites, such as resident BM macrophages and a subset of splenic red pulp macrophages, but also by macrophages in lymphoid microenvironments, such as splenic marginal metallophils and lymph node subcapsular and medullary macrophages. Here, SER is thought to be involved in the interaction between stromal macrophages and activated $T$ cells and plasmablasts (Damoiseaux et al., 1991).

\subsection{Macrophage activation markers}

A fourth category of macrophage markers comprises antigens induced by activating agents. Induced expression of such activation markers is accompanied by, and in the ideal situation indicative of, specific functional acquisitions. Generic activation markers, however, do not exist, since the phenotypic and functional response of a macrophage depends greatly on the nature of both the stimulus and the responding cell. Yet, IFN- $\gamma$ is a major stimulator of multiple macrophage functions, and was therefore chosen as a "model activating agent" to identify macrophage activation markers. As the following discussion will show, many of the present activation markers are also induced by other agents.

Expression of MHC class II antigens, in the mouse $\mathrm{H}-2 \mathrm{Ia}$, is induced in most macrophages by IFN- $\gamma$, as well as by a number of other stimuli including IL-4, GM-CSF and IL-3 (Steeg et al., 1982; Crawford et al, 1987; Willman et al., 1989; Frendl and Beller, 1990). On the other hand, IFN- $\alpha / \beta$ and M-CSF have been shown to counteract the IFN- $\gamma$ - or GM-CSF-mediated induction of Ia expression (Ling et al., 1985; Willman et al., 1989). Colony-forming macrophage precursors do not express Ia antigens (Miller et al., 1985), but expression is induced during in vitro development in about $15-30 \%$ of the cells (unpublished observation; Falk et al., 1988). This apparent heterogeneity is not clonally determined, however (Yen et al., 1987). Expression of Ia molecules is a prerequisite for macrophages to present antigen to $\mathrm{CD} 4^{+} \mathrm{T}$ helper cells, but not a 'proof' of their ability to do so; productive stimulation of Th cells requires appropriate co-stimulatory signals in addition to Ia-bound antigenic peptides (Liu and Linsley, 1992).

LFA-1 (CD11a/CD18) belongs to the integrin family and shares its $\beta$-chain type with Mac-1 and $\mathrm{p} 150 / 95$ (CD11b and CD11c, respectively). Expression of LFA-1 is already found on immature cells, since part of $\mathrm{BM} \mathrm{M}-\mathrm{CFC}$ is $\mathrm{LFA}^{+}{ }^{+}$ (Miller et al., 1985). Yet, among more mature cells, LFA-1 can be considered a marker of primed and activated stages and its expression can be induced by several stimulants including IFN- $\gamma$, LPS, IL-4 and IL-3 (Strassmann et al., 1985; Frendl and Beller, 1990). Various macrophage populations, however, are refractory with respect to the induction of LFA-1 (Strassmann et al., 1985). As an integrin, LFA-1 is critically involved in many cellular interactions and is a ligand for ICAM-1, ICAM-2 and possibly others. However, to be functional, the LFA-1 molecule needs to be activated to reach a high-affinity state (Figdor et al., 1990). Therefore, expression of LFA-1 is a sign of potential, but not necessarily actual, involvement in LFA-1-ICAM interactions.

The major ligand of LFA-1, ICAM-1 (CD54), may also be considered a macrophage activation marker. Expression of this member of the immunoglobulin superfamily is induced by a variety of inflammatory cytokines, including IFN- $\gamma$, IL- 1 and TNF- $\alpha$ (Dustin and Springer, 1988). ICAM-1 shows a widespread cellular and tissue distribution, including vascular endothelium, lymphocytes, monocytes, macrophages and dendritic leukocytes (Prieto et al., 1989). This suggests that the ICAM-1-LFA-1 interaction is probably regulated at the level of activation of the LFA-1 molecule.

The antigen 158.2 is another IFN- $\gamma$-inducible marker for macrophages in both mature and immature stages of development (Koestler et al., $1984 ; 1985)$. In addition, expression of 158.2 can be induced by LPS, but not by IFN- $\alpha / \beta$, muramyl dipeptide or bestatin. The initial characterization of this marker suggested a link between enhanced 158.2 expression and tumoricidal 
and/or bactericidal activity of macrophages. In our hands, however, IFN- $\gamma$ also induces high level expression of this marker in macrophage precursor cells without inducing concomitant cytotoxic activities (unpublished results). 158.2 is weakly expressed by resident macrophages, but can be demonstrated at significant levels on exudate macrophages as well as exudate granulocytes.

MBR-2 is one of a cluster of antigenic determinants on the same or closely associated molecules (Martin et al., 1988). Initially, this marker was defined on a subpopulation of $B$ cells, but its presence on macrophages and erythrocytes was also recognized (Kung et al., 1982). In contrast to the activation markers described above, MBR-2 is induced by IFN- $\gamma$ only on macrophages in the more mature stages of development (unpublished). Expression of MBR-2 is not fully dependent on induction by IFN- $\gamma$, however, since macrophages maturing in vitro show increasing expression of MBR-2 in the absence of IFN- $\gamma$ stimulation (Falkenberg et al., 1989). Resident peritoneal macrophages also express significant levels of MBR-2. The immunohistochemical profile of anti-MBR mAbs is characterized particularly by reactivity with capillary endothelia.

The TM-2, TM-4, and TM-5 antibodies were raised against IFN- $y$ stimulated RAW264 macrophage tumor cells in order to obtain markers for intermediate stages in the tumoricidal activation pathway (Paulnock and Lambert, 1990; D.M. Paulnock, personal communication). As such, these antigens are expressed by stimulated RAW264 cells, but not by IFN- $\gamma$-stimulated WEHI-3 cells that cannot be induced to express tumoricidal activity. Likewise, resident peritoneal macrophages, which cannot be induced to kill tumor cells, fail to express these antigens after stimulation. Induction of TM-2, -4 and -5 expression by responsive cells is relatively specific for IFN- $\gamma$ exposure, since IFN- $\alpha / \beta$, TNF- $\alpha$, LPS, IL-4 and GM-CSF are ineffective in this respect. Analysis of TM-antigen profiles of different exudate macrophage populations revealed a more complex pattern, suggesting that TM-4 and -5 antigens are associated with an inflammatory phenotype, while induction of TM-2 occurs dur- ing the later stages of activation to tumoricidal activity.

\section{Concluding remarks}

The available mAbs against mouse mononuclear phagocyte markers, of which the current panel is only a selection, permit us to identify different stages in the development of these cells. Using multiple markers from each category, we feel confident in determining from the cellular phenotype whether macrophages are immature, mature, belong to a specific subset, or are more or less stimulated. This classification is still rather crude, and definitely needs further refinement. This, however, can only be achieved when more insight is obtained into the developmental relationships between the various members of the mononuclear phagocyte system and the phenotypic hallmarks that identify the different stages. Considering the "rudimentary" classification, caution should be exercised in drawing conclusions from results obtained with single markers, since many experimental conditions unexpectedly induce or suppress the expression of particular antigens. Such an "aberrant" phenotype is likely to have functional significance. This, however, remains elusive until the function of the irregularly up- or down-modulated antigen has been clarified. Unfortunately, many markers described in this overview still lack a functional designation, thus leaving us with "good guesses" in relating the cellular phenotype to a specific cellular function. A major effort of the forthcoming years, therefore, will be to transform these "good guesses" into "solid evidence" by elucidating the functions of the various macrophage markers and translating these in terms of cellular capabilities.

\section{Acknowledgements}

We thank Dr. Gerd Burmeister from BMA Biomedicals AG and Drs. Paul Crocker, Ute and Frank Falkenberg, Siamon Gordon, Hans de Jong, Mark Jutila, Georg Kraal, Philippe Naquet, Donna Paulnock, Clemens Sorg and Tim Springer 
for providing antibodies and/or hybridomas included in the panel discussed in this paper.

\section{References}

Adams, D.O. and Hamilton T.A. (1984) The cell biology of macrophage activation. Annu. Rev. Immunol. 2, 283.

Austyn, J.M. and Gordon, S. (1981) F4/80, a monoclonal antibody directed specifically against the mouse macrophage. Eur. J. Immunol. 11, 805.

Beller, D.I., Springer, T.A. and Schreiber, R.D. (1982) AntiMac-1 selectively inhibits the mouse and human type three complement receptor. J. Exp. Med. 156, 1000.

Bhattacharya, A., Dorf, M.E. and Springer, T.A. (1981) A shared alloantigenic determinant on Ia antigens encoded by the I-A and I-E subregions: evidence for I region gene duplication. J. Immunol. 127, 2488.

Brown, E.J. (1991) Complement receptors and phagocytosis. Curr. Opin. Immunol. 3, 76.

Cherayil, B.J., Weiner, S.J. and Pillai, S. (1989) The Mac-2 antigen is a galactose-specific lectin that binds IgE. J. Exp. Med. 170, 1959.

Crawford, R.M.., Finbloom, D.S., Ohara, J., Paul, W.E. and Meltzer, M.S. (1987) B cell stimulating factor-1 (interleukin 4) activates macrophages for increased tumoricidal activity and expression of Ia antigens. J. Immunol. 139, 135.

Crocker, P.R. and Gordon, S. (1989) Mouse macrophage hemagglutinin (sheep erythrocyte receptor) with specificity for sialylated glycoconjugates characterized by a monoclonal antibody. J. Exp. Med. 169, 1333.

Damoiseaux, J.G.M.C., Döpp, E.A. and Dijkstra, C.D. (1991) Cellular binding mechanism on rat macrophages for sialylated glycoconjugates, inhibited by the monoclonal antibody ED3. J. Leukocyte Biol. 49, 434.

De Jong, J.P., Nikkels, P.G.J., Piersma, A.H. and Ploemacher, R.E. (1987) Erythropoiesis and macrophage subsets in medullary and extramedullary sites. In: I.N. Rich (Ed.), NATO ASI Series H, Vol. 8, Molecular and Cellular Aspects of Erythropoietin and Erythropoiesis. SpringerVerlag, Berlin, p. 237.

De Jong, J.P., Voerman, J.S.A., Van der Sluijs-Gelling, A.J., Willemsen, R. and Ploemacher, R.E. (1994a) A monoclonal antibody (ER-HR3) against murine macrophages: I. Ontogeny, distribution and enzyme histochemical characterization of ER-HR3-positive cells. Cell Tissue Res. 275, 567.

De Jong, J.P., Leenen, P.J.M., Voerman, J.S.A., Van der Sluijs-Gelling, A.J. and Ploemacher, R.E. (1994b) A monoclonal antibody (ER-HR3) against murine macrophages: II. Biochemical and functional aspects of the ER-HR3 antigen. Cell Tissue Res. 275, 577.

Dijkstra, C.D., Van Vliet, E., Döpp, E.A., Van der Lely, A.A. and Kraal, G. (1985) Marginal zone macrophages identified by a monoclonal antibody: characterization of im- muno- and enzyme-histochemical properties and functional capacities. Immunology 55, 23.

Drevets, D.A., Leenen, P.J.M. and Campbell, P.A. (1993) Complement receptor type 3 involvement is essential for killing of Listeria monocytogenes by mouse macrophages. J. Immunol. 151, 5431.

Dustin, M.L. and Springer, T.A. (1988) Lymphocyte functionassociated antigen-1 (LFA-1) interaction with intercellular adhesion molecule-1 (ICAM-1) is one of at least three mechanisms for lymphocyte adhesion to cultured endothelial cells. J. Cell Biol. 107, 321.

Ezekowitz, R.A.B. and Gordon, S. (1982) Down-regulation of mannosyl receptor-mediated endocytosis and antigen F4/80 in bacillus Calmette-Guerin-activated mouse macrophages. Role of $\mathrm{T}$ lymphocytes and lymphokines. J. Exp. Med. 155, 1623.

Falk, L.A., Wahl, L.M. and Vogel, S.N. (1988) Analysis of Ia antigen expression in macrophages derived from bone marrow cells cultured in granulocyte-macrophage colonystimulating factor or macrophage colony-stimulating factor. J. Immunol. 140, 2652.

Falkenberg, U., Leenen, P.J.M. and Falkenberg, F.W. (1989) Characterization of mouse macrophage differentiation antigens by monoclonal antibodies. Cell. Immunol. 124, 77.

Figdor, C., Van Kooyk, Y. and Keizer, G.D. (1990) On the mode of action of LFA-1. Immunol. Today 11, 277.

Flotte, T.J., Springer, T.A. and Thorbecke, G.J. (1983) Dendritic cell and macrophage staining by monoclonal antibodies in tissue sections and epidermal sheets. Am. J. Pathol. 111, 112.

Frendl, G. and Beller, D.I. (1990) Regulation of macrophage activation by IL-3. I. IL-3 functions as a macrophageactivating factor with unique properties, inducing Ia and lymphocyte function-associated antigen-1 but not cytotoxicity. J. Immunol. 144, 3392.

Frigeri, L.G. and Liu, F.-T. (1992) Surface expression of functional IgE binding protein, an endogenous lectin, on mast cells and macrophages. J. Immunol. 148, 861.

Hirsch, S., Austyn, J.M. and Gordon, S. (1981) Expression of the macrophage-specific antigen $F 4 / 80$ during differentiation of mouse bone marrow cells in culture. J. Exp. Med. $154,713$.

Ho, M.-K. and Springer, T.A. (1982) Mac-2, a novel $32000 \mathrm{M}_{\mathrm{r}}$ mouse macrophage subpopulation-specific antigen defined by monoclonal antibodies. J. Immunol. 128, 1221.

Holmberg, L.A., Springer, T.A. and Ault, K.A. (1981) Natural killer activity in the peritoneal exudates of mice infected with Listeria monocytogenes: characterization of the natural killer cells by using a monoclonal rat anti-murine antibody (M1/70). J. Immunol. 127, 1792.

Jansen, A., Homo-Delarche, F., Hooijkaas, H., Leenen, P.J.M., Dardenne, M. and Drexhage, H.A. (1994) Immunohistochemical characterization of monocytes-macrophages and dendritic cells involved in the initiation of the insulitis and $\beta$-cell destruction in NOD-mice. Diabetes 43, 667.

Jutila, M.A., Kroese, F.G.M., Jutila, K.L., Stall, A.M., Fiering, 
S., Herzenberg, L.A., Berg, E.L. and Butcher, E.C. (1988) Ly- $6 \mathrm{C}$ is a monocyte/macrophage and endothelial differentiation antigen regulated by interferon-gamma. Eur. J. Immunol. 18, 1819.

Jutila, M.A., Berg, E.L., Kroese, F.G.M., Rott, L., Perry, V. and Butcher E.C. (1993) In vivo distribution and characterization of two novel mononuclear phagocyte differentiation antigens in mice. J. Leukocyte Biol. 54, 30.

Kleist, R., Schmitt, E., Westermann, J. and Mühlradt, P.F. (1990) Modulation of Forssman glycosphingolipid expression by murine macrophages: coinduction with class II MHC antigen by the lymphokines IL4 and IL6, Immunobiology $180,405$.

Koestler, T.P., Rieman, D., Muirhead, K., Greig, R.G. and Poste, G. (1984) Identification and characterization of a monoclonal antibody to an antigen expressed on activated macrophages. Proc. Natl. Acad. Sci. USA 81, 4505.

Koestler, T.P., Badger, A.M., Rieman, D.J., Greig, R. and Poste, G. (1985) Induction by immunomodulatory agents of a macrophage antigen recognized by monoclonal antibody 158.2 and correlation with macrophage function. Cell. Immunol. 96, 113.

Kraal, G. (1992) Cells in the marginal zone of the spleen. Int. Rev. Cytol. 132, 31.

Kraal, G. and Janse, M. (1986) Marginal metallophilic cells of the mouse spleen identified by a monoclonal antibody. Immunology 58, 665 .

Kraal, G., Rep, M. and Janse, M. (1987) Macrophages in T and $B$ cell compartments and other tissue macrophages recognized by monoclonal antibody MOMA-2. An immunohistochemical study. Scand J. Immunol. 26, 653.

Kraal, G., Janse, M. and Claassen, E. (1988) Marginal metallophilic macrophages in the mouse spleen: effects of neonatal injections of MOMA-1 antibody on the humoral immune response. Immunol. Letters 17, 139.

Kraal, G., Ter Hart, H., Meelhuizen, C., Venneker, G. and Claassen, E. (1989) Marginal zone macrophages and their role in the immune response against $\mathrm{T}$-independent type 2 antigens: modulation of the cells with specific antibody. Eur. J. Immunol. 19, 675.

Kung, J.T., Sharrow, S.O., Ahmed, A., Habbersett, R., Scher, I. and Paul, W.E. (1982) B lymphocyte subpopulation defined by a rat monoclonal antibody, 14G8. J. Immunol. 128, 2049.

Leenen, P.J.M. and Campbell, P.A. (1993) Heterogeneity of mononuclear phagocytes. An interpretive review. In: M.A. Horton (Ed.), Blood Cell Biochemistry, Vol. 5, Macrophages and Related Cells. Plenum Press, New York, p. 29.

Leenen, P.J.M., Jansen, A.M.A.C. and Van Ewijk, W. (1986) Murine macrophage cell lines can be ordered in a linear differentiation sequence. Differentiation 32, 157.

Leenen, P.J.M., Melis, M.L. and Van Ewijk, W. (1987) Single cell immuno- $\beta$-galactosidase staining of heterogeneous populations. Practical application on limited cell numbers. Histochem. J. 19, 497.
Leenen, P.J.M., Slieker, W.A.T., Melis, M. and Van Ewijk, W. (1990a) Murine macrophage precursor characterization. I. Production, phenotype, and differentiation of macrophage precursor hybrids. Eur. J. Immunol. 20, 15.

Leenen, P.J.M., Melis, M., Slieker, W.A.T. and Van Ewijk, W. (1990b) Murine macrophage precursor characterization. II. Monoclonal antibodies against macrophage precursor antigens. Eur. J. Immunol. 20, 27.

Leenen, P.J.M., Melis, M., Slieker, W.A.T. and Van Ewijk, W. (1991) Do ER-MP23 ${ }^{+}$connective tissue macrophages constitute a separate lineage of macrophage differentiation? J. Leukocyte Biol. 2 (suppl.), 63.

Leenen, P.J.M., Melis, M., Kraal, G., Hoogeveen, A.T. and Van Ewijk, W. (1992) The monoclonal antibody ERBMDM1 recognizes a macrophage and dendritic cell differentiation antigen with aminopeptidase activity. Eur. J. Immunol. 22, 1567.

Ling, P.D., Warren, M.K. and Vogel, S.N. (1985) Antagonistic effect of interferon- $\beta$ on the interferon- $\gamma$-induced expression of Ia antigen in murine macrophages. J. Immunol. $135,1857$.

Liu, Y. and Linsley, P.S. (1992) Costimulation of T-cell growth. Curr. Opin. Immunol. 4, 265.

Malorny, U., Michels, E. and Sorg, C. (1986) A monoclonal antibody against an antigen present on mouse macrophages and absent from monocytes. Cell Tissue Res. 243, 421.

Martin, C., Willmer, U., Falkenberg, F.W. and Dorf, M.E. (1988) Serological characterization of macrophage hybridomas: identification of an interferon- $\gamma$-inducible surface marker. Cell. Immunol. 112, 187.

McCormack, J.M., Leenen, P.J.M. and Walker, W.S. (1993) Macrophage progenitors from mouse bone marrow and spleen differ in their expression of the Ly-6C differentiation antigen. J. Immunol. 151, 6389.

McFarland, H.I., Nahill, S.R., Maciaszek, J.W. and Welsh, R.M. (1992) CD11b (Mac-1): A marker for $\mathrm{CD}^{+}$cytotoxic $\mathrm{T}$ cell activation and memory in virus infection. $\mathrm{J}$. Immunol. 149, 1326.

McGarry, M.P. and Stewart, C.C. (1991) Murine eosinophil granulocytes bind the murine macrophage-monocyte specific monoclonal antibody F4/80. J. Leukocyte Biol. 50, 471 .

Miller, B.A., Antognetti, G. and Springer, T.A. (1985) Identification of cell surface antigens present on murine hematopoietic stem cells. J. Immunol. 134, 3286.

Miyama-Inaba, M., Kuma, S.-I., Inaba, K., Ogata, H., Iwai, H., Yasumizu, R., Muramatsu, S., Steinman, R. and Ikehara, S. (1988) Unusual phenotype of B cells in the thymus of normal mice. J. Exp. Med 168, 811.

Mühlradt, P.F., Monner, D.A. and Dijkstra, C.D. (1989) Immunohistochemical localization of Forssman glycosphingolipid-positive macrophages and reticular cells in murine lymphoid tissue. Immunobiology 179, 259.

Nibbering, P.H., Leijh, P.C.J. and Van Furth, R. (1987) Quantitative immunocytochemical characterization of mononuclear phagocytes. I. Monoblasts, promonocytes, mono- 
cytes, and peritoneal and alveolar macrophages. Cell. Immunol. 105, 374.

Paulnock, D.M. and Lambert, L.E. (1990) Identification and characterization of monoclonal antibodies specific for macrophages at intermediate stages in the tumoricidal activation pathway. J. Immunol. 144, 765.

Penn, P.E., Jiang, D.-Z., Fei, R.-G., Sitnicka, E. and Wolf, N.S. (1993) Dissecting the hematopoietic microenvironment. IX. Further characterization of murine bone marrow stromal cells. Blood 81, 1205.

Pierres, M., Goridis, C. and Goldstein P. (1982) Inhibition of murine $\mathrm{T}$ cell-mediated cytolysis and $\mathrm{T}$ cell proliferation by a rat monoclonal antibody immunoprecipitating two lymphoid cell surface polypeptides of 94000 and 180000 molecular weight. Eur. J. Immunol. 12, 60.

Prieto, J., Takei, F., Gendelman, R., Christenson, B., Biberfeld, P. and Patarroyo, M. (1989) MALA-2, mouse homologue of human adhesion molecule ICAM-1 (CD54). Eur. J. Immunol. 19, 1551.

Rosen, H. (1990) Role of CR3 in induced myelomonocytic recruitment: insights from in vivo monoclonal antibody studies in the mouse. J. Leukocyte Biol. 48, 465.

Rutherford, M.S., Witsell, A. and Schook, L.B. (1993) Mechanisms generating functionally heterogeneous macrophages: chaos revisited. J. Leukocyte Biol. 53, 602.

Sadahira, Y., Mori, M., Awai, M., Watarai, S. and Yasuda, T. (1988) Forssman glycosphingolipid as an immunohistochemical marker for mouse stromal macrophages in hematopoietic foci. Blood 72, 42.

Slieker, W.A.T., De Rijk-De Bruijn, M.F.T.R., Leenen, P.J.M. and Van Ewijk, W. (1993a) ER-MP12 antigen, a new cell surface marker on mouse bone marrow cells with thymusrepopulating ability: I. Intrathymic repopulating ability of ER-MP12-positive bone marrow cells. Int. Immunol. 5, 1093.

Slieker, W.A.T., Van der Loo, J.C.M., De Rijk-De Bruijn, M.F.T.R., Godfrey, D.I., Leenen, P.J.M. and Van Ewijk, W. (1993b) ER-MP12 antigen, a new cell surface marker on mouse bone marrow cells with thymus-repopulating ability: II. Thymus-homing ability and phenotypic characterization of ER-MP12-positive bone marrow cells. Int. Immunol. 5, 1099.

Springer, T.A. (1978) Monoclonal xenogeneic antibodies to murine cell surface antigens: identification of novel leukocyte differentiation antigens. Eur. J. Immunol. 8, 539.

Springer, T.A., Galfré G., Secher, D.S. and Milstein, C. (1979)
Mac-1: a macrophage differentiation antigen identified by monoclonal antibody. Eur. J. Immunol. 9, 301.

Steeg, P.S., Moore, R.N., Johnson, H.M. and Oppenheim, J.J. (1982) Regulation of murine macrophage Ia-antigen expression by a lymphokine with immune interferon activity. J. Exp. Med. 156, 1780.

Strassmann, G., Springer, T.A. and Adams, D.O. (1985) Studies on antigens associated with the activation of murine mononuclear phagocytes: kinetics of and requirements for induction of lymphocyte function-associated (LFA)-1 antigen in vitro. J. Immunol. 135, 147.

Takei, F. (1985) Inhibition of mixed lymphocyte response by a rat monoclonal antibody to a novel murine lymphocyte activation antigen (MALA-2). J. Immunol. 134, 1403.

Van der Meer, J.W.M., Van de Gevel, J.S. and Van Furth, R. (1983) Characteristics of long-term cultures of proliferating mononuclear phagocytes from bone marrow. J. Reticuloendothel. Soc. 34, 203.

Van Rooijen, N., Claassen, E., Kraal, G. and Dijkstra, C.D. (1989) Cytological basis of immune functions of the spleen. Progr. Histochem. Cytochem. 19, 1.

Van Vliet, E., Melis, M. and Van Ewijk, W. (1985) Marginal zone macrophages in the mouse spleen identified by a monoclonal antibody. Anatomical correlation with a B cell subpopulation. J. Histochem. Cytochem. 33, 40.

Walker, E.B., Akporiaye, E.T., Warner, N.L. and Stewart, C.C. (1985) Characterization of subsets of bone marrowderived macrophages by flow cytometry analysis. J. Leukocyte Biol. 37, 121.

Willman, C.L., Stewart, C.C., Miller, V., Yi, T.-L. and Tomasi, T.B. (1989) Regulation of MHC class II gene expression in macrophages by hematopoietic colony-stimulating factors (CSF). Induction by granulocyte/macrophage CSF and inhibition by CSF-1. J. Exp. Med. 170, 1559.

Wijffels, J.F.A.M., De Rover, Z., Kraal, G. and Beelen, R.H.J. (1993) Macrophage phenotype regulation by colony-stimulating factors at bone marrow level. J. Leukocyte Biol. 53, 249.

Witmer, M.D. and Steinman, R.M. (1984) The anatomy of peripheral lymphoid organs with emphasis on accessory cells: light-microscopic immunocytochemical studies of mouse spleen, lymph node, and Peyer's patch. Am. J. Anat. 170, 465.

Yen, S.-E., Beelen, R.H.J. and Walker, W.S. (1987) Expression of Ia antigen in colonies of bone marrow-derived macrophages. J. Leukocyte Biol. 42, 697. 